\title{
Thermal Shock Failure Mechanism of Nanostructured Zirconia Coating by Atmospheric Plasma Spraying
}

\author{
Chang Ying, Liu Bei, Dong Shijie, Wang Huihu, Xie Zhixiong
}

Hubei University of Technology, Wuhan 430068, China

\begin{abstract}
Nanostructured zirconia coatings has been prepared based on reasonable spraying technical parameters and the corresponding thermal shock property of the as-sprayed coating was examined at $1100{ }^{\circ} \mathrm{C}$. The structure and the surface/interface morphology of the coatings have been analyzed using X-ray diffraction (XRD), metallographic microscope, scanning electron microscopy (SEM), energy dispersive spectrum (EDS) and transmission electron microscopy (TEM). Based on the detailed analysis of the structure and phase composition, a rational mechanism has been proposed for thermal shock failure of the coating. Compared with other nanoparticles, those particles close to pores and pre-existing microcracks would preferentially grow up during the thermal shock process due to a better growth space. The growth of these nanoparticles is conducive to the formation of new microcracks which would lead to the growth of the other nanoparticles. With the growth of most or all of the nanoparticles, the nanostructured zirconia coating correspondingly changes into the quasi-microstructured coating. The thermal shock failure mode of the as-sprayed coating is similar to that of traditional zirconia thermal barrier coatings (TBCs).
\end{abstract}

Key words: thermal shock failure; zirconia coating; atmospheric plasma spraying

Plasma spraying zirconia thermal barrier coatings (TBCs) have been widely used in hot section components of gas turbine and diesel engines such as burners, transition ducts, shrouds, blades and vanes for their low thermal conductivity and thermal expansion coefficient which are close to that of the base metal ${ }^{[1,2]}$, and the application of TBCs could reduce aero engine turbine blade surface temperature by about $200{ }^{\circ} \mathrm{C}^{[3]}$. However, with the development of aviation gas turbines to high flow, high temperature and high thrust-weight ratio, the gas combustion temperature could get to more than $1650^{\circ} \mathrm{C}$, or even be expected to reach $1930^{\circ} \mathrm{C}$ in the future ${ }^{[3,4]}$. The high temperature alloy and TBCs coatings widely used nowadays would be irresistible to the harsh working conditions. Therefore, it is urgent to find a new thermal barrier coating.

It has been reported that nanostructured thermal barrier coatings have lower thermal conductivity coefficient, higher thermal expansion coefficient and better mechanical performance in comparison with conventional zirconium oxide coatings ${ }^{[5]}$, which make them a new generation of thermal barrier coating materials. As for the thermal performance process of nanostructured zirconia coating, current research is mainly focused on its thermal expansion coefficient and thermal diffusion coefficients ${ }^{[6,7]}$. In the present study, we aim to investigate and test the thermal shock property of the nanostructured zirconia coating. According to the experimental results, a rational thermal shock failure mechanism of as-sprayed coating will be proposed.

\section{Experiment}

Feedstock powders with spherical shape and primary grain size of $25 \mathrm{~nm}$ (Fig.1), which are mainly composed of tetragonal phase zirconia, prepared via the coupling route of w/o emulsion with urea homogenous precipitation reported in previous works ${ }^{[8,9]}$, were used to deposit the nanostructured zirconia coating. Plasma spraying process was carried out using a Sulzer-Metco F9-MB plasma gun mounted on an ABB

Received date: March 25, 2016

Foundation item: National Natural Science Foundation of China (51004046, 51075129); Wuhan Youth Chenguang Program of Science and Technology (2013070104010016); Middle-aged and Young Program of Educational Commission of Hubei Province (Q20101409)

Corresponding author: Dong Shijie, Professor, School of Mechanism, Hubei University of Technology, Wuhan 430068, P. R. China, E-mail: dongsjsj@ mail.hust.edu.cn

Copyright $($ C 2017, Northwest Institute for Nonferrous Metal Research. Published by Elsevier BV. All rights reserved. 


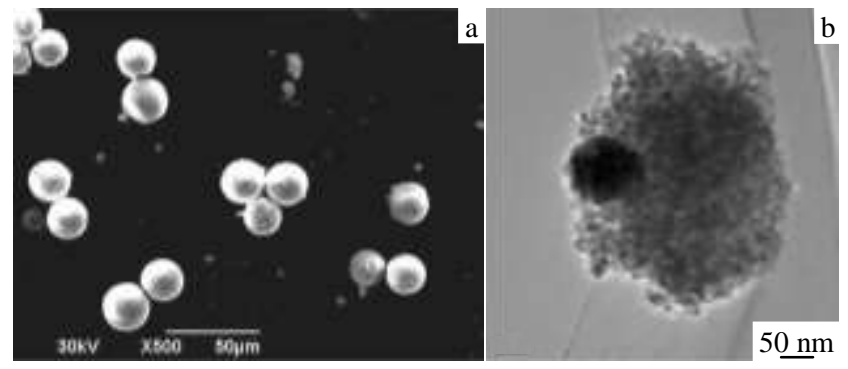

Fig. 1 SEM (a) and TEM (b) micrographs of zirconia powders

robot. $1 \mathrm{Cr} 18 \mathrm{Ni} 9 \mathrm{Ti}$ stainless steel plates with dimensions of 40 $\mathrm{mm} \times 30 \mathrm{~mm} \times 3 \mathrm{~mm}$ were used as substrates. Prior to the spraying, the substrates were cleaned with acetone and grit-blasted with alumina abrasive. In order to minimize the thermal expansion performance difference between substrate material and zirconia ceramic material, a $100 \mu \mathrm{m}$ metal transition layer (bonding layer) was sprayed between the substrate material and the top ceramic material. The metal feedstock powders with a chemical composition of $\mathrm{Ni}-22 \mathrm{Cr}-10 \mathrm{Al}-1 \mathrm{Y}$ (wt\%) and particle sizes ranging from 38 $\mu \mathrm{m}$ to $75 \mu \mathrm{m}$ used for transition layer were the Amdry365-2 manufactured by the Sluzer Metco company. During the spraying process, the substrates were cooled by circulating water and the surfaces of coatings by compressed air. The process parameters of transition layer and surface ceramic layer are shown in Table 1.

According to aviation industry standard HB 7269-96, the thermal shock test was carried out in a muffle furnace. When the temperature of the furnace reached up to $1100{ }^{\circ} \mathrm{C}$, the samples were pushed into the furnace and held for about 10 $\min$ at $1100^{\circ} \mathrm{C}$, and then they were directly quenched into water with room temperature for 2 min until the temperature of samples became the same as that of water according to thermometer measurement. After being taken out from water, the samples were dried and the surface and interface cracks of the samples were examined with the 10 times magnifying glass, then the samples were put into the $1100{ }^{\circ} \mathrm{C}$ furnace again to repeat the above-mentioned process. When a visible TBC failure area (spallation plus delamination) reaches about $5 \%$ of the total area, the thermal shock cycling was stopped, and the number of cycling was recorded and defined as the thermal shock failure lifetime of nanostructured zirconia coating.

Table 1 Spray process parameters of atmospheric plasma spraying

\begin{tabular}{ccc} 
spraying & NiCrAlY & $\mathrm{ZrO}_{2}(3 \mathrm{Y})$ \\
\hline Powder & 31.5 & 42 \\
Power/kW & 450 & 610 \\
Current/A & 100 & 250 \\
Coating thickness $/ \mu \mathrm{m}$ & 100 & 100 \\
Spray distance $/ \mathrm{mm}$ & 55 & 20 \\
Powder quality/g. $\mathrm{min}^{-1}$ & 37 & 35 \\
Argon flow $/ \mathrm{L} \cdot \mathrm{min}^{-1}$ & & \\
\hline
\end{tabular}

The surface and the cross-section morphology of the coating samples were determined by metallographic microscope and scanning electron microscopy (SEM), the particle sizes and morphologies of the feedstock powders and coatings by transmission electron microscopy (TEM), and the crystalline phases of ceramic layer by X-ray diffractometry (XRD). EDX-GENESIS60S energy dispersive spectrometer was employed to study the surface ingredients of the coatings.

\section{Results and Discussion}

\subsection{Analysis of surface morphology}

The surface and cross-section SEM micrograph of the failure sample is shown in Fig.2. Fig.2a reveals that the partial spallation exists inside the surface ceramic coating of the sample. In addition, it's obvious that a crack appears at the interface between bonding layer and surface ceramic layer, shown in Fig.2b, which indicates that the ceramic layer could also wholly spall from bonding layer surface. According to the fatigue theory ${ }^{[10]}$, the layer interface of coating belongs to weak structural interface. During thermal shock process, when the coating samples were taken out from the high temperature furnace and quickly quenched in water at room temperature, very large stress is developed inside the coating due to the difference of thermal expansion coefficients between ceramic layer and bonding layer. At the same time, thermal grown oxide (TGO) could come into being in the coating. Under the action of cycling thermal stress and structure stress (oxidation stress), cracks would propagate along the layer interface and result in ceramic layer spallation from bonding layer.

Actually, according to the SEM micrograph of the failure sample surface (Fig.2a), the surface ceramic layer does not entirely spall along the interface between bonding layer and ceramic layer, but partly spalls from the inside of the zirconia ceramic coating. The causes of this phenomenon could be interpreted as follows: when the as-sprayed coating is heated and quenched, the ceramic layer is subjected to cycling thermal stress, which leads to the formation of microcracks. On the one hand, the microcracks could reduce concentration of stress resulted from the thermal expansion coefficient mismatch between the ceramic layer and the bonding layer by releasing stress inside the surface ceramic layer to prolong

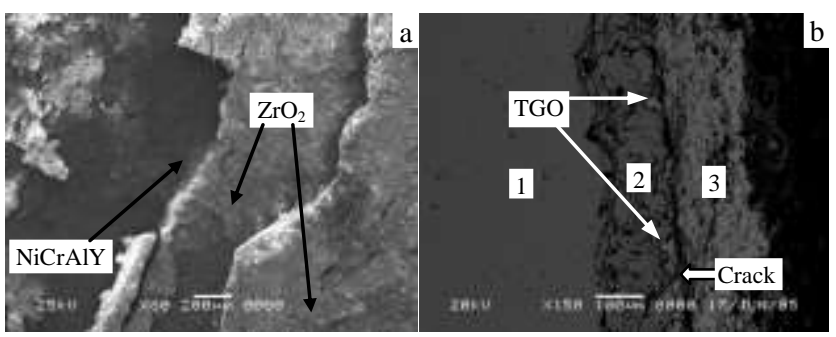

Fig. 2 SEM micrographs of surface (a) and cross-section (b) of failure sample (1, 2, 3 represent substrate, bonding layer and ceramic layer, respectively) 
thermal cycling lifetime of the as-sprayed coating. On the other hand, the microcracks could also result in the internal spallation of ceramic layer.

\subsection{Phase composition of the coating}

Fig. 3 reveals the XRD patterns of surface ceramic layer before and after thermal shock test. The position of peaks doesn't change, which indicates that there is not structure stress originating from transformation of tetragonal-to-monoclinic phase during thermal shock process. Meanwhile, it also shows that zirconia is composed of tetragonal or cubic phase. In addition, the spectrum peaks in Fig.3b are sharper than that in Fig.3a, which means that the crystallites of the coating have further grown up during thermal shock process.

Appearance of the failure sample demonstrates that there is a residual white ceramic layer on the outside surface of bonding layer when the ceramic layer spalls from bonding layer, and the XRD patterns of the outside surface of bonding layer and of the inner surface of ceramic layer are shown in Fig.4. Fig.4a indicates that the main crystal phase is still tetragonal or cubic phase zirconia. Meanwhile, according to the XRD pattern of the outside surface of bonding layer, the existence of a very minor $\mathrm{Al}_{2} \mathrm{O}_{3}$ peak in Fig.4a shows the tiny effect of oxidation stress (TGO) on thermal shock failure of the coating ${ }^{[11]}$. Recent studies show that proper TGO would

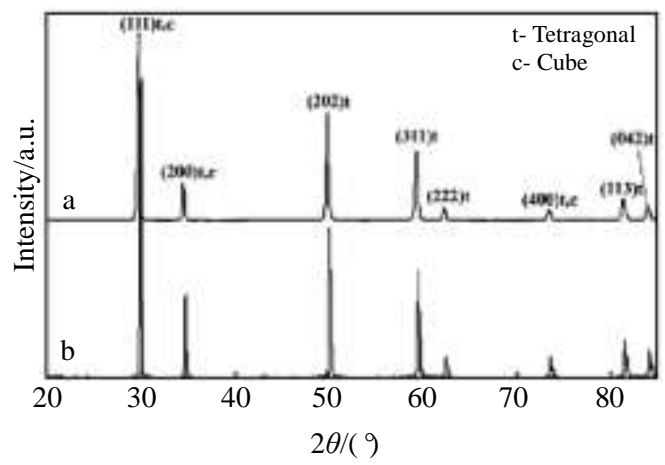

Fig. 3 XRD patterns of surface ceramic layer before (a) and after (b) thermal shock failure

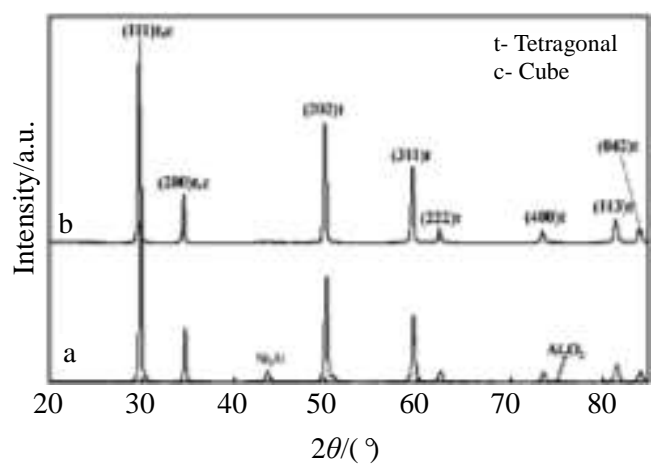

Fig. 4 XRD patterns of the outside surface of bonding layer (a) and the inner surface of ceramic layer (b) create a gradual thermal expansion-coefficient change between bonding layer and ceramic layer and contribute to the TBCs' thermal-shock resistance. Meanwhile, excessive TGO growth would lead to a higher thermal expansion-coefficient mismatch and weaken the bond strength between bonding layer and ceramic layer, thus against the thermal-shock resistance of $\mathrm{TBCs}^{[12,13]}$. Therefore, the tiny effect of oxidation stress should not be the main cause of thermal shock failure.

\subsection{Analysis of thermal shock failure mechanism}

According to the theory of thermal shock failure ${ }^{[14-17]}$, the thermal shock stress plays a key role in the failure process of coating during thermal shock test. Because of the different thermal expansion coefficients of metal and ceramic, the thermal stress will generate when the coating sample is heated and quenched. The cyclical change of heating and cooling process during thermal shock test has caused the cyclical change of stress. The previous study shows that there should be a definite fatigue limit of coating material ${ }^{[18]}$. When cyclic stress is higher than fatigue limit of the coating, cracks will come into being inside the coating. Because of the weak structural interface of coating ${ }^{[10]}$, the cracks will propagate along the interface of surface ceramic layer and bonding layer. For traditional thermal barrier coating, when the oxidation degree of metal bonding layer is not serious, the thermal expansion mismatch stress can be released by microcracks and pores between ceramic surface layer and bonding layer. However, with continuous exposure of samples to thermal cycles, the oxide layer originating from high-temperature oxidation of bonding layer will grow along microcracks and pores between ceramic surface layer and bonding layer and occupy the position of microcracks and pores. Therefore, the thermal expansion mismatch stress can't be released by microcracks and pores between ceramic surface layer and bonding layer, finally resulting in spallation of surface ceramic coating.

Fig.5a and $5 \mathrm{~b}$ reveal the interface morphologies of ceramic surface layer and metal bonding layer before and after failure. It can be seen that the interface structure of Fig.5b is very similar to that of Fig.5a, which means that bonding layer oxidation does not occur in Fig.5b. Further observation indicates that the large crack location of the failure sample, as shown in Fig.5b, is similar to the microcracks location in Fig.5a, which demonstrates that the large crack of the failure sample probably come from the growth of the pre-existing microcrack.

Fig.6 shows micrographs and corresponding marked zone EDS spectra of the ceramic layer located in interface of surface/bonding. We can see that the metal elements $(\mathrm{Ni}, \mathrm{Cr}$, $\mathrm{Al}$ and $\mathrm{Y}$ ) of bonding layer go into the internal pore of zirconia surface ceramic layer by diffusion, which is beneficial to the increase of interface combination strength of the as-sprayed coating.

Fig.7a reveals the particle size of as-sprayed zirconia 


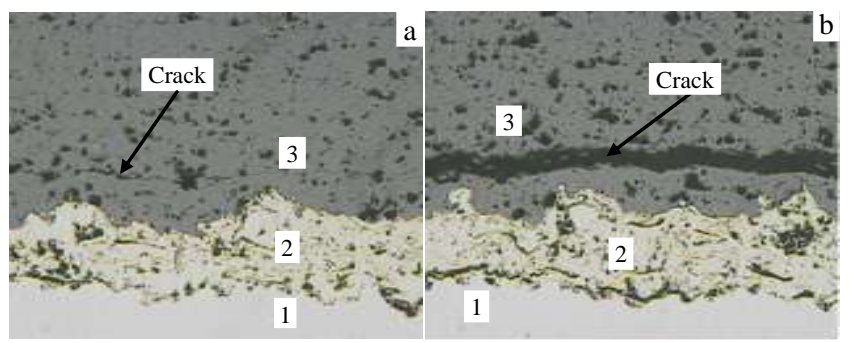

Fig. 5 Cross section microstructure of sample before (a) and after (b) 32 time thermal shock failure (1, 2 and 3 represent substrate, bonding layer and ceramic layer, respectively)

ceramic surface layer is mainly comprised of the equiaxed grains smaller than $70 \mathrm{~nm}$. For comparison, the particle size of the ceramic layer after 20 time thermal shock cycles shown in Fig.7b is dramatically different from that in Fig.7a, which is mainly comprised of equiaxed grains about $100 \mathrm{~nm}$. It means that the nanoparticles of ceramic layer grow up during thermal shock test process.

At present, it is clear that the thermal shock resistance capability of the coating (including nanostructured coating or traditional coating) depends on the number and distribution of pores and microcracks, which play the role of stress-relieved center ${ }^{[17-19]}$. In this study, the pores and pre-existing microcracks of the as-sprayed coating could provide a better growth space for the nanoparticles, and those nanoparticles close to them would preferentially grow up during the thermal shock process with the increase of temperature. The growth of these nanoparticles is conducive to the formation of new microcracks, which would lead to the growth of other nanoparticles. The above-mentioned two factors, including the growth time of nanoparticles and the formation of new microcracks resulting in relatively low stress, which is
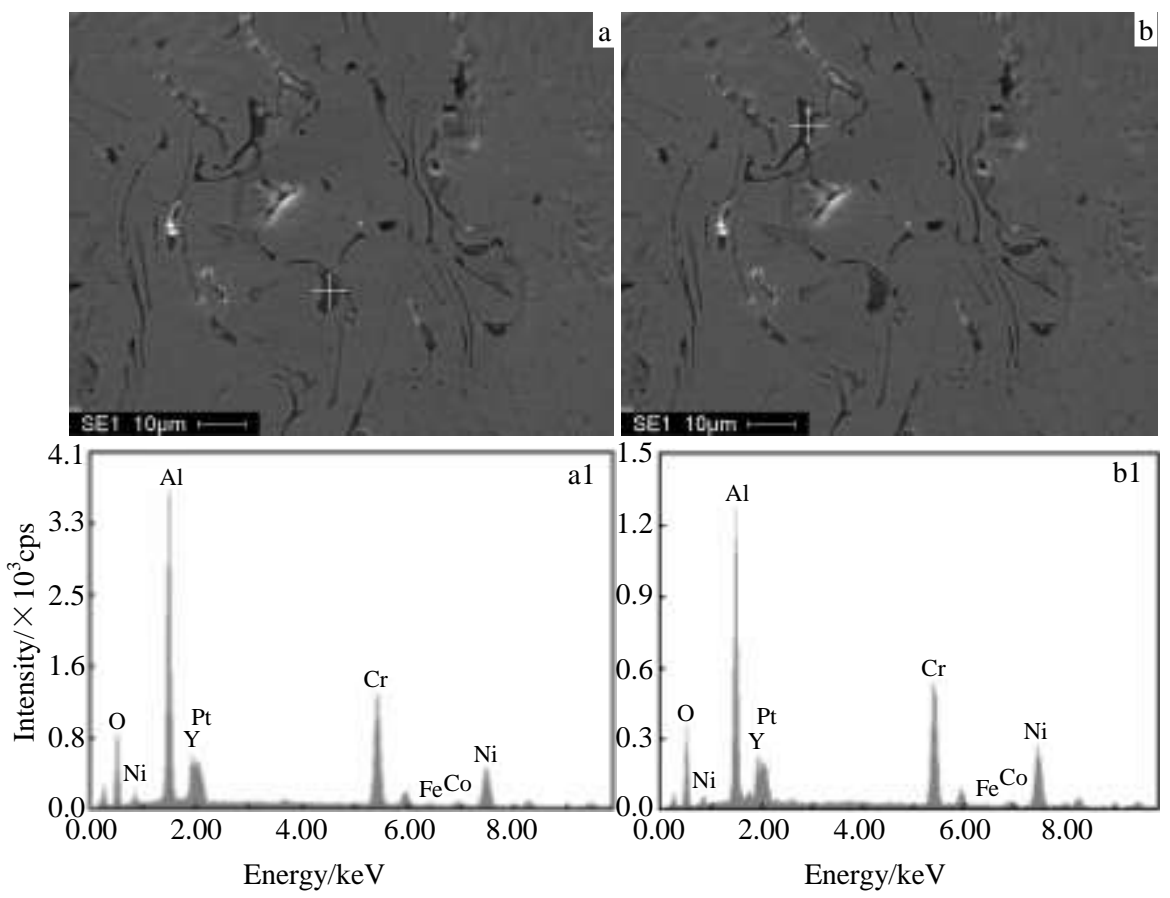

Fig. 6 SEM micrographs $(a, b)$ and corresponding marked zone EDS spectra of the ceramic layer located in interface of surface/bonding $\left(a_{1}, b_{1}\right)$

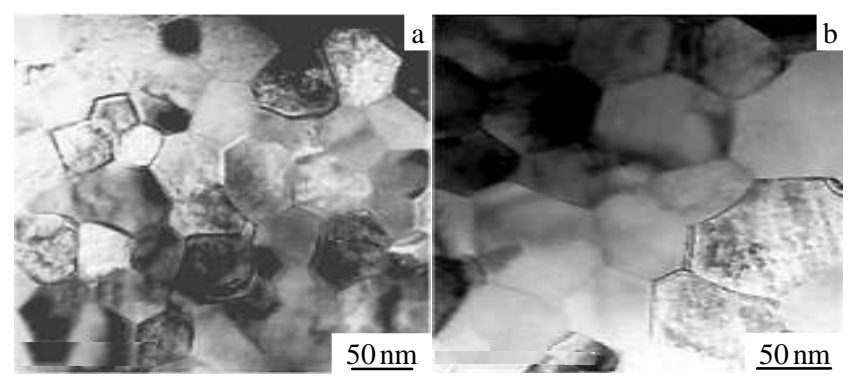

Fig. 7 TEM micrographs of particle sizes of as-sprayed ceramic layer before (a) and after (b) thermal shock cycles beneficial to thermal shock performance, would prolong the thermal cycling lifetime of nanostructured coating, and they are the reasons why the nanostructured coating has longer thermal cycling lifetime compared with traditional coating ${ }^{[20]}$. Meanwhile, it is possible for the pre-existing microcracks to grow into large cracks just as shown in Fig.5. Finally, due to the growth of nanoparticles, the nanostructure of the coating would turn into the traditional quasi-microstructure. Thereupon, its thermal shock failure mode would be similar to that of traditional coating ${ }^{[17-19]}$.

\section{Conclusions}


1) The nanoparticles close to pores and pre-existing microcracks preferentially grow up during the thermal shock process due to a better growth space. The growth of these nanoparticles is conducive to the formation of new microcracks which will lead to the growth of other nanoparticles.

2) With most or whole nanoparticles growing up, the nanostructure of the coating accordingly changes into quasimicrostructure, and its thermal shock failure mode will be similar to that of traditional coating.

\section{References}

1 Gay P A, Limat J M, Steinmann P A et al. Surface \& Coatings Technology[J], 2007, 202: 1167

2 Gu S, Lu T J, Hass D D et al. Acta Materialia[J], 2001, 49: 2539

3 Jiang X L, Liu C B, Liu F. Journal of Materials Science and Technology[J], 2007, 23: 449

4 Richard C, Kowandy C, Landoulsi J et al. International Journal of Refractory Metals \& Hard Materials[J], 2010, 28: 115

5 Han Zhihai, Xu Bingshi, Wang Haijun et al. Surface \& Coatings Technology[J], 2007, 201: 5253

6 Jamali H, Mozafarinia R et al.Current Nanoscience[J], 2012, 8: 402

7 Zhou Changhai, Zhang Qiuming, Li Yao. Surface \& Coatings Technology[J], 2013, 217: 70

8 Ying Chang, Shijie Dong, Huihu Wang et al. Materials Research
Bulletin[J], 2012, 47: 527

9 Ying Chang, Shijie Dong, Huihu Wang et al. Chemistry Letter [J], 2012, 41: 883

10 Cheng Yuren, Miu Longxiu, Hou Binglin. Fatigue Strength[M] Beijing: China Railway Press, 1990: 11 (in Chinese)

11 Cao Xuan, Ma Zhuang, Liu Yanbo et al. Rare Metal Materials and Engineering[J], 2013, 42(6): 1134

12 Chen W R, Wu X, Marple B R et al. Surface and Coatings Technology[J], 2006, 201: 1074

13 Cao F, Tryon BC, Torbet J et al. Acta Materialia[J], 2009, 57: 3885

14 Chen Zun, Mabon Jim, Wen Jianguo et al. Journal of the European Ceramic Society[J], 2009, 29: 1647

15 Hsurh C H, Haynes J A, Lance M. Journal of the American Ceramic Society[J], 1999, 82: 1073

16 Sodeoka S, Suzuki M, Iniue T et al. Surface Engineering $[\mathrm{J}]$, 1998, 14: 152

17 Elizabeth Withey, Christopher Petorak, Rodney Trice et al. Journal of the European Ceramic Society[J], 2007, 27: 4675

18 Miller R A. Thin Solid Films[J],1982, 95: 250

19 Zheng Qingxing. Engineering Fracture Mechanics[J], 1996, 53: 49

20 Abbas M, Guoh B, Shahid M R. Ceramics International[J], 2013, 39: 475

\section{等离子喷涂纳米氧化锆涂层的热震失效机理研究}

常 鹰, 刘 备, 董仕节, 王辉虎, 谢志雄

(湖北工业大学, 湖北 武汉 430068)

摘 要: 采用合理的喷涂工艺参数制备了纳米氧化锆涂层并在 $1100{ }^{\circ} \mathrm{C}$ 下测试了其热震性能, 利用 $\mathrm{X}$ 射线衍射 (XRD), 扫描电镜 (SEM) 和透射电镜 (TEM) 对涂层的结构及表面/界面形貌进行了分析。根据实验分析结果提出了纳米涂层的热震失效机理, 即孔隙或早期存 在的微裂纹由于能提供更好的生长空间而使得附近的纳米颗粒在热震实验过程中优先长大, 其长大过程会造成新的微裂纹生成, 从而导 致其它的纳米颗粒长大。随着纳米结构涂层中的大多数或者全部的纳米颗粒长大后, 纳米结构随之变为准微米结构, 其热震失效模式将 类似于传统微米涂层的失效方式。

关键词：热震失效；氧化锆涂层；大气等离子喷涂

作者简介: 常 鹰, 男, 1976 年生, 博士, 教授, 湖北工业大学材料科学与工程学院, 湖北 武汉 430068, E-mail: cy0025@mail.hbut.edu.cn 